\title{
MECHANICAL PROFILING OF COMMERCIAL GRADE BIODEGRADABLE PLASTIC FILMS POST EXPOSURE TO NATURAL AND ACCELERATED WEATHERING
}

\author{
SULTAN MAJED AL-SALEM ${ }^{1}$, AFAF YA'QOUB AL-NASSER ${ }^{1}$, MAJED HAMEED AL-WADI ${ }^{1}$, \\ HANAN HMOUD SULTAN ${ }^{1}$, HAJAR JAWAD KARAM ${ }^{1}$, AYYAD TOMAN AL-DHAFEERI ${ }^{2}$, \\ MOHAMMAD AL-FOUDAREE ${ }^{1} \&$ ZAKIA RASHEED $^{1}$ \\ ${ }^{1}$ Environment and Life Sciences Research Centre, Kuwait Institute for Scientific Research, Kuwait \\ ${ }^{2}$ Water Research Centre, Kuwait Institute for Scientific Research, Kuwait
}

\begin{abstract}
Market standards for plastic products are typically governed by mechanical properties that manufacturers and converters adhere to. However, in the case of biodegradable plastic film products, namely bags used on the market, the standards must convey more environmentally related factors. In this paper, mechanical profiling of three commercial grade market products were tested. The plastic films were deemed biodegradable of oxo-biodegradable nature containing calcium carbonate $(\mathrm{CaCO} 3)$ amongst other prodegradant chemical agents. The evaluation of mechanical properties was conducted in laboratory conditions to determine the impact of exposing the samples to various degradation media, in accordance to ASTM D 882. Experiments were conducted using a universal testing machine $(50 \mathrm{kN}$ load cell) set to a $500 \mathrm{~mm}$ min-1 test speed. The measured properties included Young's modulus (MPa), ultimate stress (MPa), ultimate strain (\%), stress at break (MPa), strain at break (\%) and force at break (N). The width and thickness of the film specimens were measured using an internally calibrated Vernier callipers to the nearest $0.1 \mathrm{~mm}$. Processing and cutting variation was minimal between the width and the thickness over the length of some samples accounting for less than $1 \%$ of total number of samples measured. The determination of the mechanical properties was conducted post accelerated and natural weathering as per the standard test methods of ASTM D 4329 and ASTM D 5272, respectively. Statistical analysis utilizing the means of one-way analysis of variance (ANOVA) was also conducted among the samples exposed to natural weathering with respect to variables of meteorological conditions and primary/secondary airborne pollutants. The change of the mechanical properties has led to the understanding of the response of polymeric films deemed as biodegradable in response to exposure to natural environment, where waste minimization and standard development can be achieved for future mitigation.
\end{abstract}

Keywords: strain, oxo-biodegradable, polymer, stress, biodegradable plastic.

\section{INTRODUCTION}

In the current climate, there is a surge of controversy surrounding the topic of plastics. Undeniably and unavoidably, plastics have become a crucial part of this generation. However, the inappropriate disposal of plastic waste, as well as, the increase in consumption provokes serious environmental issues. The rising environmental awareness on a global scale has imposed considerable pressure for associated authorities to take actions. This includes the research into alternative options to conventional plastics which is latched on to a negative reputation. Nevertheless, the greenness of these so-called environmentally friendly alternatives is often questionable. This is especially true when the routes of biodegradation are in question, i.e. oxo-biodegradation and hydro-biodegradation. Since April 2015, the European Parliament and the European Council established Directive EU 2015/720 [1]; which is an amendment of Directive 94/62/EC [2] as regards to reducing the consumption of lightweight plastic carrier bags. Subsequently, the directive aims to reduce the level of littering of these bags which accumulates in the environment where more plastics related problems (i.e. marine pollution) aggravates. 
The official (bio)degradation mechanism for oxo-degradable plastic is defined by the British Standard as a "degradation mechanism resulting from oxidative and cell-mediated phenomena, either simultaneously or successively" [3]. This definition is also referenced in CEN/TR 15351: 2006. However, it must be emphasised that only the process is defined, but the terminology "oxo-degradation" is not standardised. In the current market, there are conventional plastics enriched with additives which aim to aid in the degradation process when initiated by the presence of oxygen and accelerated by light and/or heat. This type of plastics can be divided into two groups. The first group is accountable for the majority of these additivated plastics which is called oxo-degradable plastics. The behaviour of biodegradable polymers (in general) and oxo-biodegradable plastics (in particular) under weathering tests and exposure to climatic conditions is a scant topic in literature.

Materials exposed to certain conditions in the outdoors, will deteriorate with time. These materials include synthetic polymers, including common polyolefin (PO) plastics such as polyethylene (PE) and polypropylene (PP), as well as elastomers, wood, hair, wool, skin protein and cellulose [4]. Majority of PO polymers are used in the packaging industry among other applications. In Europe, out of the 58 million tonnes produced in the year 2015, about $40 \%$ went to satisfy the packaging sector's demand [5]. Other applications of such materials will typically include indoor products oriented for customer use such as carrier bags and outdoor products such as mulches, plastics covers and greenhouses. These materials will degrade over time slowly due to exposure to solar radiation in a photodegradation induced mechanism, losing their integrity and attributes. Other influencing parameters have a major contribution on the rate of photodegradation were temperature, humidity and other meteorological conditions contribute immensely to it. However, it was deemed that ultra violet (UV) levels and exposure is the most significant factor resulting in breaking the polymer chains, producing radicals and reducing the molecular weight of the polymer. When these polymers are exposed to the natural weather and start to degrade due to a negative influence of environment, the process is called weathering [6]. A detailed discussion on the influence of UV and climatic conditions impact on polymeric materials can be found elsewhere [7]-[9].

The intensity of light due to solar radiation that reaches to the surface of the earth is associated with the breakage of these chemical bonds that tie polymer chains together. The solar radiation that reaches the surface of the earth is based on wave lengths between 295 and $2500 \mathrm{~nm}$. Solar radiation between 280 and $315 \mathrm{~nm}$ is termed UVB and has an energy of 426$380 \mathrm{~kJ} \mathrm{~mol}^{-1}$. UVA has an energy of 389 and $300 \mathrm{~kJ} \mathrm{~mol}^{-1}$ between the wave lengths of 315 and $400 \mathrm{~nm}$ [10]. Only $4-6 \%$ of the solar radiation that reaches the earth's surface is capable of breaking chemical bonds $(290-400 \mathrm{~nm})$ [11]. Based on the aforementioned principles, weathering tests have been established and standardised to determine the loss of products integrity after exposure.

In this work, and following the current needs of both governmental and private entities alike within the state of Kuwait; three commercial grade oxo-biodegradable film products are studied within the scope of this communication. The products are claimed to be both biodegradable under climatic conditions of Kuwait, and of oxo-biodegradable origin. The products were assessed for their biodegradability and their properties under climatic conditions are reported with respect to accelerated and natural weathering tests. The mechanical profile of the specimens was investigated as an indicator to the degradation profile of the materials. 


\section{MATERIALS AND METHODS}

\subsection{Samples acquirement and assessment}

Three types of plastic bags used in the Kuwaiti market were secured from local dealers with their main characteristics depicted in Table 1. The samples acquired were presumed to be environmentally friendly and biodegradable, which were secured from various sources within the state. The samples were cut into standard testing dimension specimens accepted by international protocols for thin plastic film characterization as described previously in [12]-[14].

Table 1: Types and description of plastic bags considered for testing [12]-[14].

\begin{tabular}{l|c|c}
\hline Biodegradable bag type & Application & Average thickness per test specimen \\
\hline Type 1 - Yellow in colour & Trash bag & $70 \mu \mathrm{m}$ \\
\hline Type 2 - Pigmented with blue & Trash bag & $40 \mu \mathrm{m}$ \\
\hline Type 2 - Pigmented with white & Carrier bag & $30 \mu \mathrm{m}$ \\
\hline
\end{tabular}

\subsection{Fourier transformed infrared spectrometry (FTIR)}

An IS10 Thermo-Nicolet FTIR unit equipped with an attenuated reflectance (diamond) attachment was used for the analysis and the identification of material's chemical fingerprint. The test was conducted in accordance with ISO 10640. Sample were tested using 32 scans for the background and each individual spectrum in a spectra range of $4000-400 \mathrm{~cm}^{-1}$ following the methodology depicted previously in Al-Salem et al. [14] and Al-Salem [15].

\subsection{Natural weathering of film samples}

In this work, the films intended for characterization post natural weathering were arrayed over non-expanded metal trays of non-corroding aluminium mesh with openings covering $\approx 70 \%$ of its surface area in accordance with ASTM D 5272-08 [16] using design for exposure rack "A" with an approximate individual diameter of openings equal to $0.5 \mathrm{~cm}$. Each rack had seven trays, each divided into two segments allowing 60 specimens to be mounted on. All racks were placed at a $45^{\circ}$ angle as per ASTM D 1435-05 [17] and ASTM D 5272-08 [16]. The first tray was positioned at $90 \mathrm{~cm}$ from ground level, and each tray was of $15 \mathrm{~cm}$ in width and $177 \mathrm{~cm}$ in length. Two sites were chosen to simulate the impact of weather in Kuwait. The first was located in an arid area close to the bay (Shwiakh area, latitude $\mathrm{N}$ $29^{\circ} 13^{\prime} 49^{\prime \prime}$; longitude $47^{\circ} 58^{\prime} 31^{\prime \prime} \mathrm{E}$ ) with a mean annual ambient temperature of $32^{\circ} \mathrm{C}$ and relative humidity of $30 \%$. The second, Salmyia area (latitude N 29 33 '33'; longitude $48^{\circ} 8^{\prime} 33^{\prime \prime} \mathrm{E}$ ), is a seafront area with a mean annual ambient temperature of $30^{\circ} \mathrm{C}$ and relative humidity of $60 \%$. The start of the natural weathering loading was on the 26th December 2017 and were kept with the intention of exposing the samples for a continuous period of one year. The film samples were mounted on the trays with a minimum spacing of $11 \mathrm{~mm}$ between each individual specimen. The racks were facing southward direction in accordance with ASTM 1435-05. A minimum of ten specimens of each type were unloaded of each tray at each site after 1, 3, 6, 9 and 12 months for further testing and characterization. The unloaded film samples were carefully placed in plastic bags and rinsed for 3-5 s before drying and conducting the various experiments. Readers are referred to Al-Salem et al. [7] and Al-Salem [9] for more details on the methodology. 


\subsection{Accelerated ageing of test specimens}

Accelerated (artificial) indoor weathering (ageing) tests are commonly used for studying materials integrity and were conducted in this work to correlate the results obtained with natural weathering ones. Films of the study samples were exposed to accelerated weathering (AW) in accordance with ASTM D 4329. Samples were mounted on the racks facing the UV lamps with no empty spaces in the panels. This is in order to maintain a uniform repeatable test conditions. Cycle A procedure was used for general applications durability testing, i.e. $8 \mathrm{~h}$ of UV exposure at $60^{\circ} \mathrm{C}$ followed by $4 \mathrm{~h}$ of condensation at $50^{\circ} \mathrm{C}$. At the end of each continuous weathering test, the chamber was cooled to room temperature and the trays were set to rest on a flat surface for a minimum of $24 \mathrm{~h}$. Samples were laid to rest for a minimum of $72 \mathrm{~h}$ before characterization following internationally recognised methodologies and laboratory testing protocols of weathering. A minimum of four replicates were exposed to the different exposure durations in the QUV machine chamber. UV lamps irradiance was also selected according to ASTM D 4329 [18], and the lamp type was set to be $0.68 \mathrm{~W} \mathrm{~m}^{-2}$ (irradiance) for normal lamp operation, which was maintained for almost $5000 \mathrm{~h}$ of operation. The irradiance sensor was calibrated every $400 \mathrm{~h}$ of lamp operation during the UV cycle under normal test temperature. The equipment used was cleaned every $800 \mathrm{~h}$ to remove scale deposits resulting from water evaporation during the condensation cycles. Readers are referred to Al-Salem et al. [7], [8], [14] for a detailed depiction on the accelerated weathering procedure.

\subsection{Mechanical profiling}

The evaluation of mechanical properties was conducted at room temperature to determine the impact of exposing the samples to various degradation media in following ASTM D 882 [19]. Experiments were conducted using a Tinuis Olsen (UK) 50 ST Model - universal testing machine ( $50 \mathrm{kN}$ load cell) set to a $500 \mathrm{~mm} \mathrm{~min}^{-1}$ test speed. The measured properties included Young's modulus (MPa), Ultimate Stress (MPa), Ultimate Strain (\%), the stress at break $(\mathrm{MPa})$, the strain at break $(\%)$ and the force at break $(\mathrm{N})$. The width and thickness of the film specimens were measured using an internally calibrated Vernier callipers to the nearest $0.1 \mathrm{~mm}$. Processing and cutting variation was minimal between the width and the thickness over the length of some samples accounting for less than $1 \%$ of total number of samples measured. The variation not being more than $\pm 0.02 \mathrm{~mm}$ for width and $\pm 0.01 \mathrm{~mm}$ for thickness with a constant width of $10 \mathrm{~mm}$ and thickness as depicted previously. The maximum extension available was $1065 \mathrm{~mm}$ equivalent to a strain of $900 \%$. Strain at break (elongation at break) was measured based on cross head displacement and a gauge of $100 \mathrm{~mm}$. For yield strength, it was observed that some specimens showed multiple yield points and some had a distinct yield. To standardize the results for easy comparison between all specimens, it was decided to consider the first yield point as the yield strength of the specimen. The measurement values obtained came from the average of the replicate specimens stored directly from the machine's software (Horizon 10.2.5.0). The tests were conducted with a gauge grip separation of $100 \mathrm{~mm}$ as suggested by the experimental protocol followed and was also set to terminate at $75 \%$ of ultimate force. The threshold of detection was input in the test program at $3 \mathrm{~N}$. To assure accurate readings that reflects the true modulus of elasticity determined from the stress and strain curves, the grip separation was reduced to $25 \mathrm{~mm}$ for the accelerated weathering specimens at threshold limit of weathering exposure. This was done due to the fact that samples were shorter due to exposure to UV for prolonged periods of time in the weathering chamber. 


\subsection{Statistical analysis}

Analysis of variance (ANOVA) testing (F-test) for the comparison of the significant variance between two or more groups was conducted to analyse the interaction of independent variables considered in this study. These included physical properties of the different plastic types (haze (\%), light transmission $(\%)$ and $\Delta \mathrm{E}$ ), as well as the mechanical properties. Independent one-way ANOVA test was conducted amongst the studied groups with respect to the different natural weathering durations considered in this work. F values as a ratio of mean sum of squares due to treatment (MST) to mean sum of squares due to error (MSE), and $p$ values as the total number of population, were both examined to determine the dependency of the variables with respect to group. $F$ critical taken as upper limits of the normal distribution was considered as the limit of acceptance/rejection of null hypothesis. The analysis covered both sites considered in this work. Relevant pollutant levels and meteorological conditions were used to check dependency of variables on each other with respect to the dependent variables. The variables considered were as per the following to study the extent of pollutant and meteorological conditions impact of exposed samples: Particulate matter $\left(\mathrm{PM}_{10}, \mathrm{mg} \mathrm{m}^{-3}\right)$, total hydrocarbon (THC, ppm), methane $\left(\mathrm{CH}_{4}, \mathrm{ppm}\right)$, nonmethane hydrocarbons (NMHC, ppm), ozone $\left(\mathrm{O}_{3}, \mathrm{ppb}\right)$, sulphur dioxide $\left(\mathrm{SO}_{2}, \mathrm{ppb}\right)$, hydrogen sulphide $\left(\mathrm{H}_{2} \mathrm{~S}, \mathrm{ppb}\right)$, nitrogen oxides (NOx, ppb), ammonia $\left(\mathrm{NH}_{3}, \mathrm{ppb}\right)$, benzene $\left(\mathrm{C}_{6} \mathrm{H}_{6}, \mathrm{ppb}\right)$, carbon monoxide $(\mathrm{CO}, \mathrm{ppm})$, carbon dioxide $\left(\mathrm{CO}_{2}, \mathrm{ppm}\right)$, temperature $\left({ }^{\circ} \mathrm{C}\right)$, wind speed $\left(\mathrm{m} \mathrm{s}^{-1}\right)$, wind direction $\left({ }^{\circ}\right)$ and relative humidity $(\%)$. Readers are referred to AlSalem [9] for more details on the pollutants levels data collection. The analysis was conducted utilizing the means of Microsoft Office Excel 2007 - Data Analysis tool as a builtin function. The methodology has been previously reported in Al-Salem [9].

\section{RESULTS AND DISCUSSION}

\subsection{Degressive behaviour and physical deterioration}

The natural weathering test conducted in this project was achieved successfully for nine continuous months. All samples exposed to the action of weathering in this work appeared consistent and comparable by touch. Physical observations were noted as a first stage and a means of initial assessment for impact of accelerated and natural weathering on the exposed samples. Signs observed visually can lead to the early detection of deterioration and can indicate the severity of the weathering tests conducted [7]. The aim of the test as per the proposed workplan of this research, is to test the specimens after one year of continuous natural weathering at both sites. The work is ongoing to date.

The samples had a stable and gradual degradation with respect to exposure time judging by the visual appearance of the plastic films of all three types. The winter season faced in Kuwait last year was observed to be somewhat cloudy at the start of the experimentation stage with an average direct sunlight exposure of $5 \mathrm{~h}$. It should also be noted that signs of crazing and haziness were visible from the first unloading session (i.e. 30 days) on the 25 th January 2018. The notes were taken after rinsing and examining the specimens in the laboratory. More pictorial analysis is shown elsewhere [14]. It was also apparent that the photo-degradation of the PO polymers serving as substrates to the biodegradable blends, was clearly related to the meteorological conditions which accelerated the degradation process with the changes in seasons of exposure. Increase in blistering and crazing was noted with both site loadings as well, as a function of weathering time. Understanding the mechanism of photodegradation is essential to study the phenomena itself and analyse the status of the 
samples after various exposure durations. There exists various factors affect the photodegradation of polymers in the outdoors. It was apparent that chain propagation affects the samples in different rates, with respect to the sites used in this work. The combination of UV and thermal degradation at site no. 1 was apparently more severe than site no. 2 . This could be attributed to the arid nature of the first location [9]. Yousif and Haddad [10] reported that the combination of UV and ambient temperatures influence the samples to a great extent with respect to natural weathering. This goes hand in hand with the findings in this research based on the total colour change $(\Delta \mathrm{E})$ estimated and shown previously in Al-Salem [20].

It is well established that the exposure to UV is the most influential of all these factors [10]. It causes plastic products to lose integrity, dye and pigments where a clear discolouration is typically noted with the ageing [21]. Typically stabilisers are added to these materials to overcome such phenomena and enhance various mechanical properties. It was also determined that such stabilizers are added to the samples studied in this work due to the fact that samples are biodegradable in nature (as chemical analysis will reveal). The samples of Type 3 started to be more brittle after exposure to 5 months in site no. 1. This supports the claim that harsh weather with less humidity has more acute effect on the samples than humidity in site no. 2 .

\subsection{Plastic films assessment and biodegradable type investigation}

A sample of the FTIR spectra obtained from scanning the bag samples are shown in Fig. 1. The main peaks of the spectra are characteristic peaks for a PE grade plastic material. Additional peak areas that are associated with plastic additives are also visible with the IR spectroscopy. These additional areas are noted within the range of $850 \mathrm{~cm}^{-1}$ and $1450 \mathrm{~cm}^{-1}$ of the IR spectrum [14]. Type 2 showed a spectrum that is different than the other two products. No additional peak was evident at the $1450 \mathrm{~cm}^{-1}$ region and the peak at $850 \mathrm{~cm}^{-1}$ was significantly less intense when compared with the other sample bags. This is an

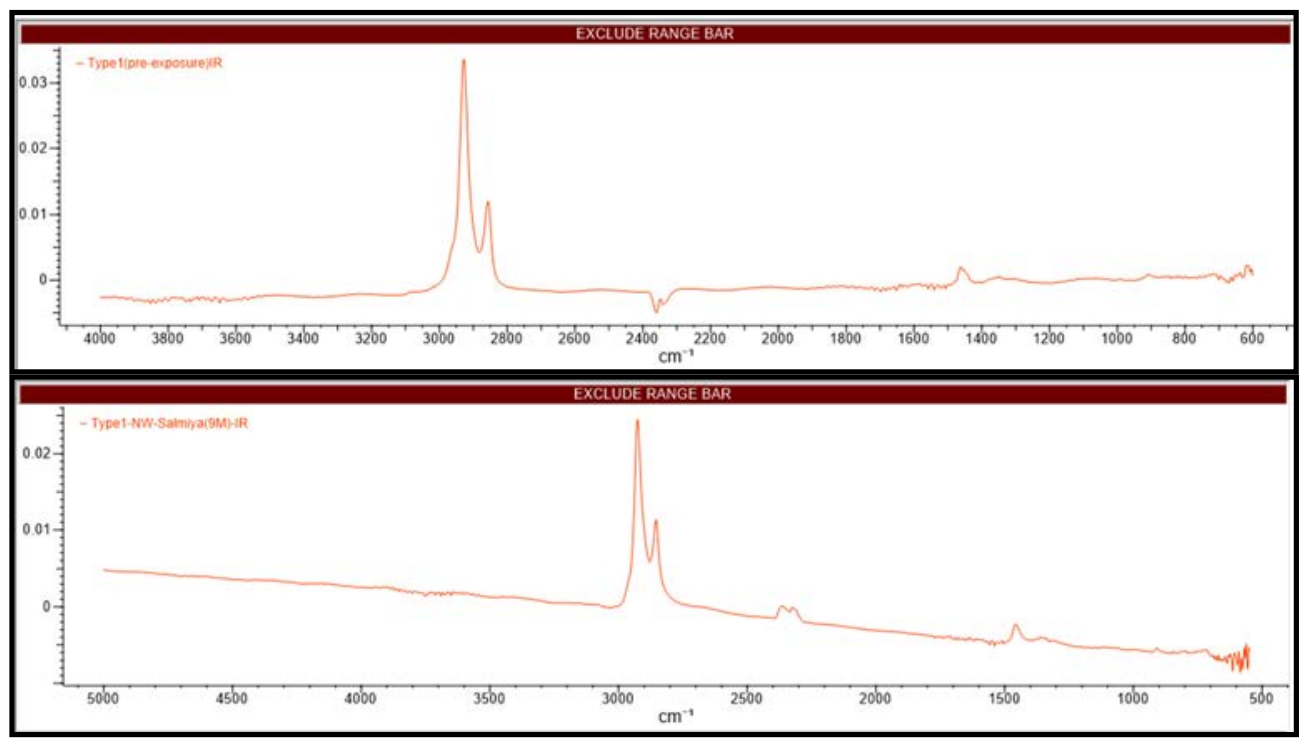

Figure 1: Sample of peak identification from FTIR analysis of Type 1 sample (preexposure (top) and after exposure to natural weathering by 9 months (bottom). 
indication that the formulation of these bags is different. From the assessment aforementioned, and depicted in our past work [12]-[14], these bags are characterized as oxobiodegradable bags with high content of calcium carbonate $\left(\mathrm{CaCO}_{3}\right)$. Readers can refer to Al-Salem et al. [14] for the thermal stability experimental results that confirm the aforementioned analysis.

Past studies have implemented similar techniques to identify the products evolved from TG/IR. The main idea of the study reported in Ewing and Kazarian [22] was the use of supercritical carbon dioxide $\left(\mathrm{scCO}_{2}\right)$ for polymeric processing which is an increasing area in industrial processes. FTIR spectroscopy provided information of the interactions between $\mathrm{CO}_{2}$ and polymers under high-pressure and supercritical conditions. It was used to study the intermolecular interactions between $\mathrm{CO}_{2}$ and polymers functionalized with different functional groups such as, a polyketone, polybutadiene, polyalcohol and polyoxime. Morphological changes were studied for polyethylene terephthalate (PET), a semi-crystalline polymer after exposing it to supercritical $\left(\mathrm{scCO}_{2}\right)$ for a range of exposure times in the work of Fleming et al. [23]. FTIR determined the $\mathrm{scCO}_{2}$-induced morphological gradient. The range of the spectra between $1320-1360 \mathrm{~cm}^{-1}$ region revealed that the $\mathrm{CO}_{2}$-induced influenced the morphological reorganization as a function of depth for about 30, 40 and $50 \mu \mathrm{m}$ for the 15, 20 and $30 \mathrm{~min}$ samples, respectively. Other studies in the investigation of the degradation profile focused on polyoxymethylene (POM)/thermoplastic polyesterurethane (TPU) by thermogravimetric analysis coupled with FTIR spectroscopy [24]. The work showed four different types of samples (i.e. POM, TPU, POM/TBU 90:10 blend and POM/TBU 80:20 blend). The work was carried out at operating conditions of heating rate equal to $20 \mathrm{~K} \mathrm{~min}^{-1}$, sample mass $=3 \mathrm{mg}$, nitrogen flow rate $=50 \mathrm{~cm}^{3} \mathrm{~min}^{-1}$ ). The FTIR spectra of gases evolved during thermal degradation of POM show peaks at $1745 \mathrm{~cm}^{-1}$ carbonyl group, and at $2800 \mathrm{~cm}^{-1}$ aldehyde group where TPU show butyl ether and formaldehyde same as the POM/TPU blends [24]. By surveying the technical literature related to the topic, it can be noted that the samples under investigation are of polyolefin nature based on the $\mathrm{CO}_{2}$ signal being detected by the IR signal. The evolution of the additives in the signal post exposure to weathering, shows that the samples are biodegradable and of commercial grade nature. The signal was compatible was past work related to plastic grades used on the market [15]. The shift in the signal for the carbon based compounds, and the loss of additives due to weathering (excluding evolved compounds from UV exposure - site no. 2) can be seen in Fig. 1 for Type 1 plastic sample.

\subsection{Mechanical profile determination}

In this section, the mechanical properties measured are reported with respect to each degradation media and exposure duration. The film samples of the various types were exposed to different durations of soil burial, accelerated and natural weathering, and the properties were measured thereafter. The accelerated weathering data are discussed at first. The degradation threshold limits determined from the accelerated weathering tests were reported in our previous work [14]. Tables 2 and 3 show a sample the mechanical properties evaluated post accelerated and natural weathering in this work. Figs 2 and 3 show a sample of the mechanical properties depicted as a function of accelerated weathering exposure. The threshold limit (i.e. point of total deformation) were determined for Types 1, 2, and 3, as 11, 13 and 19 days of continuous aging [14].

It was noted that for Types 1 and 3, the Young's modulus has increased gradually until the threshold limit of the deterioration point was reached by $7.5 \%$ and $2.8 \%$ for Types 1 and 3 , respectively. Type 2 showed a slight decrease in the modulus after $312 \mathrm{~h}$ of UV exposure 
Table 2: Mechanical properties evaluated post natural weathering (site no. 2) for Type 1.

\begin{tabular}{c|c|c|c|c|c|c|c|c}
\hline $\begin{array}{c}\text { Exposure } \\
\text { duration } \\
(\mathrm{h})\end{array}$ & $\begin{array}{c}\text { Young's } \\
\text { modulus } \\
(\mathrm{MPa})\end{array}$ & std. & $\begin{array}{c}\text { Ultimate } \\
\text { stress } \\
(\mathrm{MPa})\end{array}$ & std. & $\begin{array}{c}\text { Ultimate } \\
\text { strain } \\
(\%)\end{array}$ & std. & $\begin{array}{c}\text { Break } \\
\text { stress } \\
(\mathrm{MPa})\end{array}$ & std. \\
\hline 0 & 320.00 & 63.29 & 14.00 & 1.83 & 387.00 & 23.53 & 14.00 & 2.00 \\
30 & 281.40 & 57.27 & 13.56 & 1.75 & 356.40 & 60.90 & 13.08 & 1.71 \\
90 & 293.80 & 45.93 & 10.95 & 1.68 & 65.10 & 40.57 & 10.534 & 1.70 \\
180 & 489.60 & 43.00 & 15.76 & 1.06 & 12.47 & 2.83 & 1.01 & 0.61 \\
270 & 332.5 & 30.5 & 4.375 & 0.645 & 9.635 & 7.765 & 0.0343 & 0.0083 \\
\hline
\end{tabular}

Table 3: Mechanical properties evaluated post accelerated weathering for Type 1.

\begin{tabular}{c|c|c|c|c|c|c|c|c}
\hline $\begin{array}{c}\text { Exposure } \\
\text { duration } \\
(\mathrm{h})\end{array}$ & $\begin{array}{c}\text { Young's } \\
\text { modulus } \\
(\mathrm{MPa})\end{array}$ & std. & $\begin{array}{c}\text { Ultimate } \\
\text { stress } \\
(\mathrm{MPa})\end{array}$ & std. & $\begin{array}{c}\text { Ultimate } \\
\text { strain } \\
(\%)\end{array}$ & std. & $\begin{array}{c}\text { Break } \\
\text { stress } \\
(\mathrm{MPa})\end{array}$ & std. \\
\hline 0 & 320.00 & 6.00 & 14.00 & 1.83 & 387.00 & 23.53 & 14.00 & 2.00 \\
88 & 384.00 & 4.00 & 12.49 & 1.61 & 56.46 & 6.00 & 6.32 & 0.50 \\
176 & 283.71 & 5.00 & 11.47 & 3.83 & 78.38 & 24.00 & 2.07 & 0.09 \\
246 & 344.25 & 15.00 & 16.75 & 2.74 & 384.78 & 18.00 & 14.93 & 3.21 \\
\hline
\end{tabular}

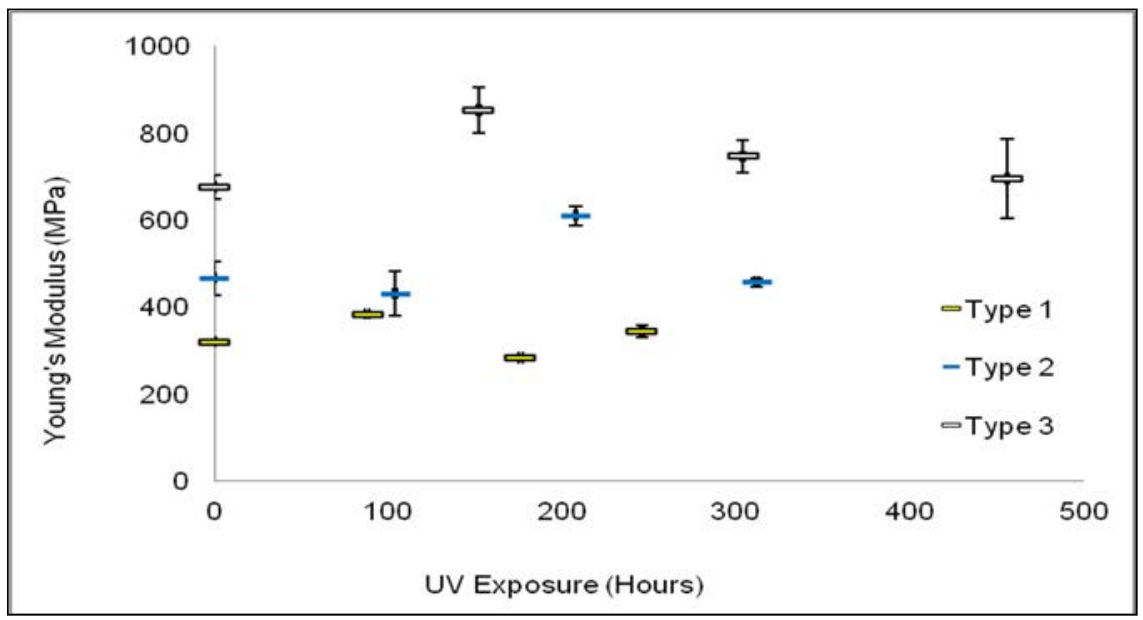

Figure 2: Young's modulus (MPa) with respect to accelerated weathering duration for the studied specimens.

by $2.5 \%$ (Fig. 2). Previous reports show that the modulus is governed by the crystallinity of polymers and the chemical changes with continuous exposure [25]-[27]. PE has a reported crystallinity of $40-60 \%$ that is highly susceptible to degradation with UV exposure and its molar masses were reported to photodegrade even with the presence of secondary antioxidants in composites [28]. Hence, an alteration to the Young's modulus was expected in this study due to crystallinity changes as a consequence of UV exposure. Parts of this discussion was shown previously in Al-Salem [9] and Al-Salem et al. [14] for various blends of polyolefin materials exposed to weathering conditions. It was suspected that the 


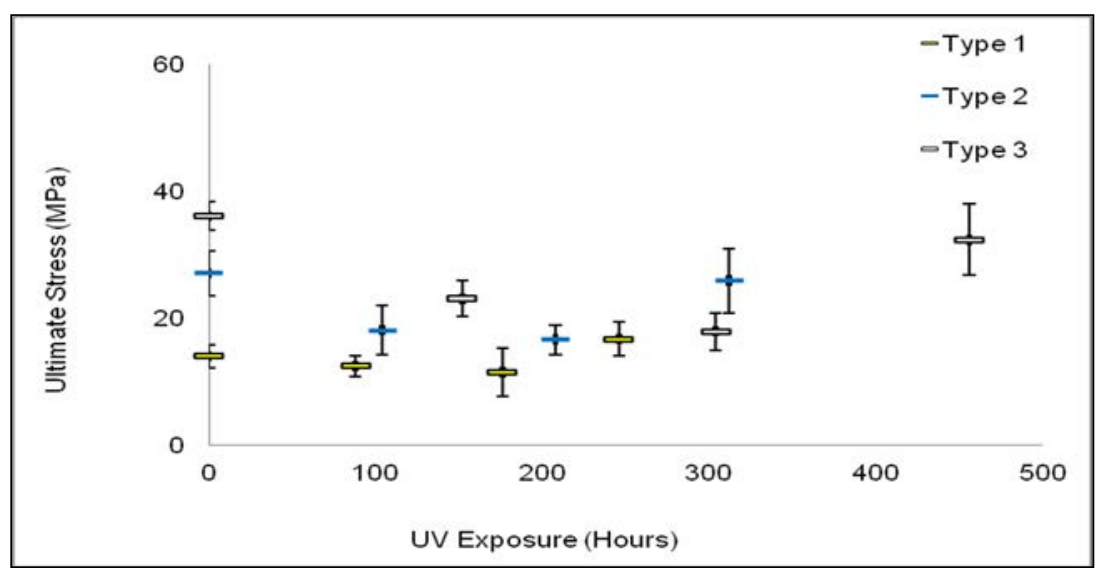

Figure 3: Ultimate stress $(\mathrm{MPa})$ with respect to accelerated weathering duration for the studied specimens.

amorphous regions in the PE had undergone degradation unlike the crystalline ones, which has remained unaffected without the formation of new crystalline regions in the polymer's matrix with weathering time [29]. However, there is a possibility of forming new crystalline regions in the matrix with PE polymers that results in an increased total crystallinity, which is attributed to the chain scission reaction of the degradation mechanism according to Sam et al. [29]. It was reported by Roy et al. [30] that natural weathering and, consequently, by mimicking its effect, accelerated weathering caused polymers to become more brittle, which was noted in this work with samples exposed to natural weathering. The embrittlement of the samples which was noted in this work with samples exposed to accelerated weathering is in agreement with the alteration in Young's modulus due to the occurrence of crack initiation from chain scission that gave rise to sufficient chain mobility, producing secondary crystallization [30].

Alexander [31] and Gulmine et al. [32] indicated that HDPE degraded very rapidly and was more prone than other PO polymers to weathering. On the other hand, Winslow [33] and Iring et al. [34] indicated that LLDPE degraded faster than other polyolefins. Hence, it was hard to pinpoint the exact polymer that could degrade faster in such products causing the collapse in the polymer's matrix which has to be judges on each case individually. PE and PP are susceptible to UV irradiation, and the mechanism of degradation has been reported previously in detail by Philip et al. [11]. This effect lead to the loss of the amorphous region in the polymers matrix due to cross-linking reactions, which lead to a change in the modulus measured at various intervals of accelerated weathering indicated by the change in the stiffness/brittleness of the samples (Figs 2 and 3).

Stress at break $(\mathrm{MPa})$ is reported with respect to the duration of accelerated weathering exposure in Fig. 3. A decreasing trend till the point of $2 / 3$ of the total duration of the accelerated weathering test. was noted with the studied samples which was expected due to cross-linking effect with exposure to UV. However, all types studied showed an increased strain value at break at threshold limit. This behaviour was related to chain scission in semicrystalline polymers, which lead to a decrease in the molecular weight of the material and consequently to a loss in strain and elongation at break with weathering [35]. The natural weathering results are shown below (Tables 2 and 3). 


\subsection{Statistical analysis of variance}

The result obtained from one way ANNOVA that revealed dependency and independency of the variables for the different properties at two sites tested three different types of polymers. With regards to site no. 1 (Shwaikh) which is noted to be arid in climate, Type 1 of the studied samples showed great dependency of haze on $\mathrm{ED}, \mathrm{PM}_{10}, \mathrm{NO}, \mathrm{NO}_{2}, \mathrm{NO}_{\mathrm{X}}, \mathrm{O}_{\mathrm{X}}, \mathrm{NH}_{3}$ and $\mathrm{RH}$. This was also noted for samples of Type 2 . The duration of the exposure leads the materials for prolonged duration of exposure under various climatic conditions that might affect the surface of the plastics exposed. This is measured with haze (\%) and was noted clearly in the analysis conducted on site no. 1. Therefore, it can be confirmed that the materials are degrading with such exposure. The thickness of the materials plays a major role in the fact that haze (\%) Type 3 was dependent on $\mathrm{ED}, \mathrm{PM}_{10}$ and $\mathrm{NO}_{\mathrm{X}}$ only. The level of oxygen in the atmosphere is suspected to be irrelevant at thicknesses below $40 \mu \mathrm{m}$. Light transmission on the other hand was noted to be dependent on $\mathrm{ED}, \mathrm{PM}_{10}, \mathrm{NO}_{\mathrm{x}}, \mathrm{O}_{\mathrm{X}}, \mathrm{NH}_{3}$ and $\mathrm{RH}$, for Type 1 of the studied samples. It was also dependent on ED, $\mathrm{PM}_{10}, \mathrm{NO}_{\mathrm{X}}, \mathrm{O}_{\mathrm{X}}$ and $\mathrm{NH}_{3}$ for Type 2. Light transmission depends on $\mathrm{ED}, \mathrm{PM}_{10}, \mathrm{NO}_{\mathrm{X}}$ and $\mathrm{NH}_{3}$ for Type 3 of the studied samples at site no. 1. It can be deduced that the light transmission is highly sensitive to days of exposure and levels of particulate matter in the air. Both Types 1 and 2 were pigmented plastic articles. $\triangle \mathrm{E}$ was dependent on $\mathrm{ED}, \mathrm{O}_{3}$, toluene, temperature and TRS for Type 1 (site no. 1) and $\mathrm{ED}$, $\mathrm{THC}, \mathrm{CH}_{4}, \mathrm{NMHC}$, toluene, benzene, o-xylene, ethylbenzene, $\mathrm{CO}$, mp-xylene, temp. and WS for Type 2 (site no. 1). Samples of Type 3 were dependent on $\triangle \mathrm{ED}, \mathrm{THC}, \mathrm{CH}_{4}, \mathrm{NMHC}$ $\mathrm{O}_{3}, \mathrm{SO}_{2}, \mathrm{H}_{2} \mathrm{~S}, \mathrm{NO}_{2}$, toluene, benzene, o-xylene, ethylbenzene, $\mathrm{CO}$, mp-xylene, temperature, WS and TRS. On a whole, $\Delta \mathrm{E}$ at site no. 1 was dependent very strongly on the exposure temperature and duration. This can be noted as a very sensible conclusion since the exposure to prolonged weathering duration will lead to loss of pigmentation.

Samples exposed to site no. 2 were also analysed for physical properties dependence on climatic conditions. Haze (\%) was noted to be very dependent on $\mathrm{ED}, \mathrm{PM}_{10}, \mathrm{NO}_{2}, \mathrm{NO}_{\mathrm{X}}, \mathrm{O}_{\mathrm{X}}$, $\mathrm{NH}_{3}$ and $\mathrm{RH}$ for samples of Type 1 (site no. 2). For Types 2 and 3, haze (\%) was dependent on $\mathrm{ED}, \mathrm{PM}_{10}, \mathrm{NO}_{\mathrm{X}}, \mathrm{O}_{\mathrm{X}}$ and $\mathrm{NH}_{3}$ (Type 2) and $\mathrm{ED}, \mathrm{PM}_{10}, \mathrm{NO}_{\mathrm{X}}$ and $\mathrm{NH}_{3}$ (Type 3). Types 2 and 3 showed that Young's modulus was highly dependent on $\mathrm{CO}_{2}$, whilst Type 1 was dependent on WD (site no. 1). However, it was dependent on WD and $\mathrm{CO}_{2}$ concentration for Types 1 and 2, respectively at site no. 2, and independent of any variable for Type 3 . Ultimate stress was strongly dependent on ED and TRS for all types in both locations. The continuation of the work will lead to better understanding to dependency of variables on climatic conditions.

\section{CONCLUSION}

Three types of biodegradable plastic bags used in the form of standard films as per international protocols for plastic characterization, were examined and studied in this work. The work aims at determining the degradation profile with respect to natural and accelerated weathering exposure. In addition, the determination of the nature and type of the bags was conducted. The following summarises the main technical findings of this work. The results can also lead to the determination of the optimal engineering standards based on the characterization campaign conducted in this research:

- Natural weathering as per internationally recognised protocols was achieved in this work. The samples of the three types were exposed to two sites. The first was noted to be of a more arid and harsh climatic conditions, where the second has a more humid climate. 
- It was noted that samples at site no. 1 were more severely crazed with respect to weathering exposure time. The samples with the lowest thickness (i.e. Type 3) were noted to deteriorate more severely especially after 5 months of continuous exposure. This was attributed to the thickness of the samples and UV penetration to the surface of the polymeric material.

- UV radiation is noted to be the most influential parameters that degrades the plastic films which leads to their photodegradation in the environment. The fact that samples exposed to arid environments have deteriorated more rapidly than the ones exposed to the humid site, indicates that starch component is not active in the formulated blends. This supports the conclusion that the samples studied contain prodegradants that are different in nature than hydro-based compounds.

- The infrared spectra identified the materials to be of polyethylene in nature containing other additives between the $850 \mathrm{~cm}^{-1}$ and $1450 \mathrm{~cm}^{-1}$ regions of the infrared spectrum. The polyethylene grade was LLDPE, LDPE and HDPE depending on the formulation of the polymeric film and the type of the material tested. Calcium carbonate $\left(\mathrm{CaCO}_{3}\right)$ was noted to be present in the plastic bags as a main oxo-biodegradable additive.

- Weatherometer results indicated that the samples are degraded under UV attack which is also consistent with oxo-biodegradable polymers. FTIR analysis for Type 1 and Type 3 after weathering revealed the presence of carbonyls, which is a direct indication of degradation.

- Type 1 of the samples had the largest change in accelerated weathering with respect to haze (\%) indicating that it was the sample with the highest change in surface chemistry.

- Type 3 of the studied samples showed the highest change in colour where $\Delta \mathrm{E}$ was estimated to be 23.001 after $456 \mathrm{~h}$ of continuous exposure to accelerated weathering [14]. This is in agreement with natural weathering tests conducted at both sites and compliments the work conducted in this research.

- The statistical analysis showed that the dependency of the haze, light transmission, $\Delta \mathrm{E}$ and mechanical properties with the specific parameters as shown in the one way ANOVA test. The significant variables on the samples tested at site no. 2 (Samlyia) on Type 1 were determined as exposure duration, ozone and total reduced sulphur. The significant variables on the samples tested at Salmiya site on Type 2 were exposure duration and total reduced sulphur. The significant variables on the sample tested at Salmiya site on Type 3 were exposure duration, ammonia, sulphur dioxide and total reduced sulphur.

- Focusing on the significant variables on the samples tested at site no. 1 (Shwaikh site) on Type 1, these were exposure duration, wind direction and total reduced sulphur. The significant variables on the sample tested at Shwaikh on Type 2 were exposure duration and total reduced sulphur. Finally, the significant variables on the sample tested at Shwaikh on Type 3 were exposure duration, sulphur dioxide and total reduced sulphur. The regression coefficient determined for both sites showed that the dependency is very weak on the aforementioned variables.

The work in this research can also direct various agencies in Kuwait and the Gulf Council Countries to develop standards that can govern the use of biodegradable plastics under climatic conditions. It can also lead to the development of various products that can be compounded with the specific needs of localities in both Kuwait and surrounding countries that suffer from harsh climatic conditions. Results so far indicate that Type 1 is an appropriate blend to be used for oxo-biodegradables in Kuwait, where the deterioration based on their mechanical profile was more rapid. Type 1 also showed signs of crazed cracks on the 
surfaces, however, during the exposure time-spans to the natural climate, the samples showed sustained modulus values.

\section{ACKNOWLEDGEMENTS}

The Project Leader would like to thank the Kuwait Institute for Scientific Research and Kuwait Municipality for funding and supporting this research project under the grant for project EM097C. The continuous support and encouragement of the management of the Environment Affairs Department of Kuwait Municipality is highly appreciated, whom have granted their approval to publish this work. The contribution of the Kuwait Foundation for the Advancement of Sciences for funding the research mission is gratefully acknowledged.

\section{REFERENCES}

[1] Directive EU 2015/720. OJ L 115 of 6/5/2015, p. 11, 2015.

[2] Directive 94/62/EC of 20/12/1994 on packaging and packaging waste. OJ L 365 of 31/12/1994, p. 10, 1994.

[3] BS 8472, Methods for the assessment of the oxo-biodegradation of plastics and of the phyto-toxicity of the residues in controlled laboratory conditions, 2011.

[4] Sionkowska, A., Modification of collagen films by ultraviolet irradiation. Polymer Degradation Stability, 68, pp. 147-151, 2000.

[5] Plastics Europe, Plastics: The Facts, an Analysis of European Plastics Production, Demand and Waste Data, 2016.

[6] Wypych, G., Handbook of Material Weathering, 4th ed., Chemtec Publishing: Toronto, 2008.

[7] Al-Salem, S.M., Abraham, G., Al-Qabandi, O.A. \& Dashti, A.M., Investigating the effect of accelerated weathering on the mechanical and physical properties of high content plastic solid waste (PSW) blends with virgin linear low density polyethylene (LLDPE). Polymer Testing, 46, pp. 116-121, 2015.

[8] Al-Salem, S.M. et al., Effect of die head temperature (DHT) at compounding stage on the degradation of linear low density polyethylene (LLDPE)/plastic film waste blends post accelerated weathering. International Journal of Polymer Science, 5147209, 2016.

[9] Al-Salem, S.M., Influential parameters on natural weathering under harsh climatic conditions of mechanically recycled plastic film specimens. Journal of Environmental Management, 230, pp. 355-365, 2019.

[10] Yousif, E. \& Haddad, R., Photodegradation and photostabilization of polymers, especially polystyrene: review. SpringerPlus, 2, 398, 2013.

[11] Philip, M., Attwood, J., Hulme, A., Williams, G. \& Shipton, P., Evaluation of weathering in mixed polyethylene and polypropylene products. The Waste and Resources Action Programme (WRAP) Report (UK), ISBN: 1-84405-092-0, 2004.

[12] Al-Salem, S.M. et al., Biodegradable films physical properties change with respect to degradation exposure to various media. Proceedings of the 7th International Conference on Engineering for Waste and Biomass Valorisation, Prague, Czech Republic, pp. 272-282, 2018.

[13] Al-Salem, S.M., Al-Nasser, S.H. \& Karam, H., In situ aerobic biodegradation in soil contact using the standard test method of ASTM D 5988-12. Proceedings of the 3rd International Conference on Energy and Environmental Science, Seoul, South Korea, 2019. 
[14] Al-Salem, S. et al., Investigating biodegradable bags standards and properties under Kuwait's environmental conditions. Annual Progress Report, KISR No. 15164, Project Code: EM097C, 2018

[15] Al-Salem, S.M., The first chemical identification of polyolefin (PO) waste blends using infrared spectroscopy. Proceedings of the 9th International Conference on Waste Management and the Environment, Seville, Spain, pp. 2-18.

[16] American Society for Testing and Materials (ASTM), Standard practice for outdoor exposure testing of photodegradable plastics, ASTM D 5272-08, Philadelphia, PA, 2013.

[17] American Society for Testing and Materials (ASTM), Standard practice for outdoor weathering of plastics, ASTM D 1435-05, Philadelphia, PA, 2005.

[18] American Society for Testing and Materials (ASTM), Standard practice for fluorescent UV exposure of plastics, ASTM D 4329, Philadelphia, PA, 2005.

[19] American Society for Testing and Materials (ASTM), Standard test method for tensile properties of thin plastic sheeting, ASTM D 882, Philadelphia, PA, 2010.

[20] Al-Salem, S.M., Waste not, want not: Standardising biodegradable plastics as a waste management mitigation strategy. Proceedings of the International Conference on Engineering Challenges in Gulf Countries, Kuwait City, Kuwait, 2019.

[21] Goldshtein, J. \& Margel, S., Synthesis and characterization of polystyrene/2- (5-chloro 2Hbenzotriazole-2-yl)-6-(1,1-dimethylethyl)-4-methyl-phenol composite microspheres of narrow size distribution for UV irradiation protection. Colloid Polymer Science, 289, pp. 1863-1874, 2011.

[22] Ewing, A.V. \& Kazarian, S.G., Current trends and opportunities for the applications of in situ vibrational spectroscopy to investigate the supercritical fluid processing of polymers. Journal of Supercritical Fluids, 134, pp. 88-95, 2018.

[23] Fleming, O.S., Chan, K.L.A. \& Kazarian, S.G., FT-IR imaging and Raman microscopic study of poly(ethylene terephthalate) film processed with supercritical $\mathrm{CO}_{2}$. Vibrational Spectroscopy, 35, pp. 3-7, 2004.

[24] Pielichowski, K. \& Leszczyñska, A., TG-FTIR study of the thermal degradation of polyoxymethylene (POM)/thermoplastic polyurethane (TPU) blends. Journal of Thermal Analysis and Calorimetry, 78, 2004.

[25] Lundin, T., Cramer, S.M., Falk, R.H. \& Felton, C., Accelerated weathering of natural fiber-filled polyethylene composites. Journal of Materials in Civil Engineering, 16, pp. 547-555, 2004.

[26] Mendes, L.C., Rufino, E.S., de Paula, F.O.C. \& Torres, A.C. Jr., Mechanical, thermal and microstructure evaluation of HDPE after weathering in Rio de Janeiro city. Polymer Degradation and Stability, 79, pp. 371-383, 2003.

[27] Mourad, A.I., Thermo-mechanical characteristics of thermally aged polyethylene/ polypropylene blends. Materials and Design, 31, pp. 918-929, 2010.

[28] Ojeda, T. et al., Degradability of linear polyolefins under natural weathering. Polymer Degradation and Stability, 96, pp. 703-707, 2011.

[29] Sam, S.T., Ismail, H. \& Ahmad, Z., Effect of cobalt stearate on natural weathering of LLDPE/soya powder blends. Polymer-Plastics Technology and Engineering, 50(9), pp. 957-968, 2011.

[30] Roy, P.K., Surekha, P., Rajagopal, C., Chatterjee, S.N. \& Choudhary, V., Studies on the photo-oxidative degradation of LDPE films in the presence of oxidised polyethylene. Polymer Degradation and Stability, 92(6), pp. 1151-1160, 2007.

[31] Alexander, M., Biodegradation: problems of molecular recalcitrance and microbial fallibility. Advance Applied Microbiology, 7, pp. 35-80, 1965. 
[32] Gulmine, J.V., Janissek, P.R., Heise, H.M. \& Akcelrud, L., Degradation profile of polyethylene after artificial accelerated weathering. Polymer Degradation and Stability, 79, pp. 385-397, 2003.

[33] Winslow, F.H., Photooxidation of high polymers. Pure and Applied Chemistry, 49, pp. 495-502, 1977.

[34] Iring, M., Foldes, E., Barabas, K., Kelen, T. \& Tudos, F., Thermal oxidation of linear low density polyethylene. Polymer Degradation and Stability, 14, pp. 319-332, 1986.

[35] Rajakumar, K., Sarasvathy, V., Thamarai Chelvan, A., Chitra, R. \& Vijayakumar, C.T., Natural weathering studies of polypropylene. Journal of Polymers and the Environment, 17, pp. 191-202, 2009. 